\title{
Produção e caracterização de biossurfactantes metabolizados por Pleurotus sajor-caju a partir de óleo de soja
}

\author{
Production and characterization \\ of biosurfactants metabolized by \\ Pleurotus sajor-caju from \\ soybean oil
}

Endi Pricila Alves ${ }^{1}$, Lorena Benathar Ballod Tavares ${ }^{2}$, Regina Maria Miranda Gern ${ }^{3}$, Denise Abatti Kasper Silva ${ }^{1}$, Sandra Aparecida Furlan ${ }^{1}$, Elisabeth Wisbeck ${ }^{1}$

\footnotetext{
${ }^{1}$ Mestrado em Engenharia de Processos, Universidade da Região de Joinville - UNIVILLE Rua Paulo Malschitzki, 10, CEP 89.219-710, Joinville, SC

e-mail: ewisbeck@univille.br, endi.pricila@,gmail.com, dabatti@univille.br, sfurlan@univille.br

${ }^{2}$ Departamento Engenharia Ambiental, Universidade Regional de Blumenau - FURB, 89030-000, Blumenau, SC e-mail: lorena@furb.br

${ }^{3}$ Programa de Pós-Graduação em Saúde e Meio Ambiente, Universidade da Região de Joinville -UNIVILLE Rua Paulo Malschitzki, 10, CEP 89.219-710, Joinville, SC e-mail: rgern@univille.br
}

\section{RESUMO}

Este estudo teve como objetivo avaliar a produção de biossurfactantes pelo fungo basidiomiceto Pleurotus sajor-caju CCB 019. A formação de biossurfactantes foi definida pela diminuição, ou seja, redução da tensão superficial $(R T \%)$ do meio de cultivo no tempo inicial e do caldo após o cultivo. Para acompanhar o crescimento micelial e a variação da tensão superficial $(\Delta T)$ do caldo de cultivo com o tempo, um biorreator de bancada (4 L) foi usado e as menores tensões superficiais ocorreram em seis dias de cultivo (144 h) $(43,4$ $\mathrm{mN} / \mathrm{m})$ no experimento $\mathrm{B} 1\left(\mathrm{~T}=34^{\circ} \mathrm{C}, \mathrm{pH}\right.$ inicial de 3 , agitação de $300 \mathrm{~min}^{-1}$, aeração de $0,25 \mathrm{~L}$. $\mathrm{min}^{-1} \mathrm{e}$ utilizando óleo de soja comercial) e 192 horas ( 8 dias) $(40,7 \mathrm{mN} / \mathrm{m})$ no ensaio B2 (as mesmas condições de B1, mas usando óleo de soja residual de fritura). O índice de emulsificação para o experimento B1, em 6 dias, foi de $66,6 \%$ e para o experimento B2, em 8 dias, foi de $65,8 \%$. Os biosurfactantes extraídos a partir dos experimentos B1 e B2 mostraram 12,0\% $\pm 0,5$ e 10,6 $\pm 0,6 \%$ de carboidratos, $7,4 \pm 0,5 \%$ e $7,7 \pm 1,0 \%$ de proteína, respectivamente. Na análise do espectro de FTIR, para ambos os experimentos, podem ser identificadas bandas confirmando a presença de carboidratos e de proteínas, também sugerindo a presença de lipídeos.

Palavras-chave: Biossurfactantes, Pleurotus sajor-caju, cultivo submerso

\section{ABSTRACT}

This study aimed to evaluate the production of biosurfactants by the fungus basidiomycete Pleurotus sajorсаju CCB 019. The biosurfactants formation was determined by the reduction of the surface tension $(R T \%)$ of the culture medium at the initial time and the culture broth at the end time. A bench top bioreactor $(4 \mathrm{~L})$ was used in order to monitor the mycelial growth and the $\Delta \mathrm{T}$ in of the culture broth with time and lower surface tensions occurred six days of cultivation $(144 \mathrm{~h})(43.4 \mathrm{mN} / \mathrm{m})$ in the experiment $\mathrm{B} 1\left(\mathrm{~T}=34{ }^{\circ} \mathrm{C}\right.$, $\mathrm{pH}$ Initial 3 , agitation of $300 \mathrm{mim}^{-1}$, aeration of $0.25 \mathrm{~L} \cdot \mathrm{mim}^{-1}$ and using commercial soybean oil) and 8 days (192 h) $(40.7 \mathrm{mN} / \mathrm{m})$ in B2 experiment (same conditions B1 but using frying residual soybean oil). The higher emulsification index for the experiment B1 in 6 days was $66.6 \%$ and for the experiment B2 at 8 days was $65.8 \%$. The biosurfactants extracted from experiments B1 and B2 showed $12.0 \% \pm 0.5$ and $10.6 \pm 0.6 \%$ carbohydrate, $7.4 \pm 0.5 \%$ and $7.7 \pm 1.0 \%$ of protein, respectively. In the analysis of the FTIR spectra for both the experiment can be identified bands confirming the presence of carbohydrates and proteins and suggests the presence of lipids. 
Keywords: Biosurfactants, Pleurotus sajor-caju, submerged cultivation

\section{INTRODUÇÃO}

Todos os dias são descartados indevidamente óleos comestíveis residuais de residências, indústrias e estabelecimentos comerciais, que tem como destino os sistemas de esgoto, causando transtornos na rede de saneamento e poluição dos recursos hídricos. O óleo, que apresenta menor densidade que a água, permanece na superfície, criando uma barreira que dificulta a entrada de luz e a oxigenação, comprometendo assim, a base da cadeia alimentar aquática 0 .

Esse problema ambiental pode ser minimizado ou até mesmo evitado por meio da coleta adequada desse resíduo. O óleo residual de frituras pode ser reutilizado como matéria-prima na fabricação de diversos produtos, tais como biodiesel 0 , sabão e detergentes 0 , biossurfactantes 0 , entre outros.

Os biossurfactantes são compostos biológicos anfifílicos produzidos extracelularmente ou como parte de membranas celulares de uma variedade de bactérias, leveduras e fungos filamentosos a partir de várias substâncias, cujas propriedades podem possibilitar sua utilização como substituintes dos surfactantes sintéti$\cos 0$.

Algumas características que fazem dos biossurfactantes produtos de grande interesse tecnológico são a elevada biodegradabilidade, baixa toxicidade, biocompatibilidade, digestibilidade, elevado poder espumante, alta seletividade e estabilidade em condições extremas de $\mathrm{pH}$, temperatura e força iônica, além de condições brandas de produção. Essas características privilegiam a sua utilização nas áreas biomédicas, de higiene pessoal e cosméticos, de alimentos e de agricultura, assim como em processos de remediação e biorremediação de solos contaminados com petróleo e ou outros tipos de óleos e por metais pesados 0 .

Atualmente, a grande maioria dos trabalhos publicados sobre produção de biossurfactantes é realizada com bactérias, porém, devido a possível natureza patogênica destas, o uso dos biossurfactantes de origem bacteriana na indústria de alimentos e nas áreas clínica e farmacêutica não são considerados adequados 0 . Entretanto já existem algumas indicações do uso de fungos para essa finalidade como o caso de leveduras do gênero Cândida 0 e de basidiomicetos do gênero Pleurotus 0 com produção de biossurfactantes poliméricos do tipo carboidrato-peptídeo-lipídeo.

Os fungos do gênero Pleurotus são cogumelos comestíveis e não apresentam risco de patogenicidade. São espécies cosmopolitas, que ocorrem naturalmente em florestas temperadas, subtropicais e tropicais e possuem um complexo enzimático lignocelulolítico específico, com enzimas como celulases, ligninases, celobiases, lacases e hemicelulases, que possibilitam a degradação de uma grande variedade de resíduos lignocelulósicos, além de serem eficientes em processos de biorremediação de solos 0 .

A produção de biossurfactantes por fungos pode ser espontânea ou induzida pela presença de compostos lipofílicos, por variações de $\mathrm{pH}$, temperatura, aeração e velocidade de agitação, ou ainda, quando o crescimento celular é mantido sob condições de estresse, como baixas concentrações da fonte de nitrogênio 0 .

Neste contexto, o presente trabalho teve por objetivo avaliar a potencialidade do fungo $P$. sajor-caju na produção de biossurfactantes usando óleo de soja como indutor e principal fonte de carbono.

\section{MATERIAIS E MÉTODOS}

\subsection{Manutenção do micro-organismo}

A espécie Pleurotus sajor-caju obtida da Coleção de Culturas de Basidiomicetos do Instituto de Botânica (São Paulo/SP) sob o código CCB 019 foi mantida em meio YMA em placas de Petri contendo (m/v): 0,3\% de extrato de levedura, $0,3 \%$ de extrato de malte, $0,5 \%$ de peptona, $1 \%$ de glicose e $2 \%$ de ágar. As placas foram mantidas a $4{ }^{\circ} \mathrm{C}$ e a reativação do micro-organismo foram realizadas mensalmente 0 .

\subsection{Preparo do inóculo}

O inóculo foi preparado em frasco de $2 \mathrm{~L}$, da marca DURAN, contendo $400 \mathrm{~mL}$ de meio YMB $(0,3 \%$ de extrato de levedura, $0,3 \%$ de extrato de malte, $0,5 \%$ de peptona, $1 \%$ de glicose e água, percentuais em $\mathrm{m} / \mathrm{v}$ ) 0 esterilizado a $120^{\circ} \mathrm{C}$ por $15 \mathrm{~min}$. O frasco foi inoculado com micélio de sete dias, raspado de uma placa de Petri. Após a inoculação, o frasco foi incubado a $30{ }^{\circ} \mathrm{C}$ e mantido sob agitação recíproca de $105 \mathrm{~min}^{-1}$, por sete dias. A fração de inóculo utilizada foi de $10 \%$, ou seja, $400 \mathrm{~mL}$ para um volume final de $4 \mathrm{~L} 0$. 


\subsection{Condução dos experimentos}

Os cultivos foram realizados em duplicata, em regime descontínuo, em reator com agitação mecânica modelo B. BRAUN, com volume útil de 5,0 L e volume de trabalho de 4,0 L. O sistema possuía três turbinas, com seis pás planas, estando a primeira turbina situada imediatamente acima do anel dispersor de ar. O diâmetro das turbinas é de $63 \mathrm{~mm}$ e a distância entre elas de $75 \mathrm{~mm}$. O meio YMB foi acrescido de $10 \%$ de óleo de soja. $\mathrm{O}$ pH inicial foi ajustado em 3 pela adição de soluções $\mathrm{HCl} 6 \mathrm{~N}$ ou $\mathrm{NaOH} 6 \mathrm{~N}$, tendo acoplado ao biorreator um sensor de pH modelo 405/DPAS-K8S/325, INGOLD ELECTRODES.

A temperatura foi controlada em $34{ }^{\circ} \mathrm{C}$ tendo acoplado no biorreator um sensor de temperatura (modelo PT 100, B. BRAUN). A vazão de ar foi mantida em $0,25 \mathrm{~L} / \mathrm{min}$ e a frequência de agitação fixada em $300 \mathrm{~min}^{-1} 0$.

Foram conduzidos dois experimentos, um com óleo de soja comercial (B1) e outro com óleo de soja residual de fritura (B2). Todos os experimentos foram realizados em duplicata. Foram retiradas cerca de 50 $\mathrm{mL}$ de amostra (a cada 48 horas) para análise da concentração de biomassa e tensão superficial.

A biomassa micelial foi separada por filtração a vácuo em papel Whatman $n^{\circ} 1$. O caldo de cultivo livre da biomassa micelial foi deixado em repouso em um béquer por aproximadamente 20 minutos, a fim de separar o óleo que passou pela filtração, que foi removido com o auxílio de uma pipeta e de papel absorvente. Este caldo de cultivo sem óleo foi congelado em tubos tipo Falcon, até a realização da análise de tensão superficial e atividade emulsificante. A remoção do óleo remanescente é necessária, pois para a análise da tensão superficial o óleo é interferente.

\subsection{Concentração de biomassa micelial}

A concentração da biomassa micelial foi determinada pelo método gravimétrico como segue: a biomassa micelial foi separada por filtração a vácuo em papel Whatman $\mathrm{n}^{\circ} 1$, lavada com água destilada até a retirada do óleo remanescente e transferida a cadinhos previamente pesados. A secagem deu-se a $105{ }^{\circ} \mathrm{C}$ até massa constante. A massa seca obtida foi dividida pelo volume da amostra, expressando-se assim a concentração celular em g/L.

\subsection{Tensão superficial}

As amostras foram descongeladas à temperatura ambiente. A tensão superficial foi determinada em um Tensiômetro Interfacial KRÜSS K8, por meio do sistema de medidas com anel de platina Du Nouy, a $25^{\circ} \mathrm{C}$, em triplicata. A tensão superficial da água destilada à temperatura ambiente é de $72 \mathrm{mN} / \mathrm{m}$ e quando o surfactante está presente, o valor da tensão superficial é reduzido [10]. Assim sendo, uma estimativa da formação de biossurfactantes foi definida pela diminuição, ou seja, redução da tensão superficial $(R T)$ do meio de cultivo no tempo inicial e do caldo após o cultivo (Equação 1).

$R T(\%)=\frac{(T i-T f)}{T i} * 100$

Onde $T i(\mathrm{mN} / \mathrm{m})$ é a tensão superficial do meio de cultivo no tempo inicial e $T_{f}(\mathrm{mN} / \mathrm{m})$ é a tensão superficial do caldo de cultivo no tempo final, sem a biomassa micelial.

\section{6 Índice de Emulsificação $\left(E_{24}\right)$ e Atividade Emulsificante $\left(A E_{a / o}\right)$}

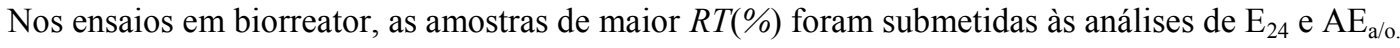

Em um tubo de ensaio foram colocados $3,5 \mathrm{~mL}$ de amostra (previamente descongelada à temperatura ambiente e devidamente diluída (diluições entre 1:10 e 1:20) e 2,0 mL de óleo de soja e misturados em agitador tipo vórtex a $700 \mathrm{mim}^{-1}$ por $1 \mathrm{~min}$. Após $24 \mathrm{~h}$ em repouso foi realizada a leitura da altura (mm) da emulsão água/óleo formada e da altura total.

O índice de emulsificação $\left(E_{24}\right.$ - \%) foi definido como a relação centesimal entre a altura da camada de emulsão e a altura total de acordo com a Equação 20.

$$
E_{24(\text { amostra })}=\frac{A_{\text {emulsão }}}{A_{\text {total }}} * 100
$$

Onde $E_{24 \text { (amostra) }}=$ índice de emulsificação (\%) ou relação centesimal entre a altura da emulsão água/óleo e a altura total, utilizando amostra; $A_{\text {emulsão }}=$ altura $(\mathrm{mm})$ da emulsão e $A_{\text {total }}=$ altura $(\mathrm{mm})$ total (altura da emulsão mais altura da camada remanescente de óleo).

A atividade emulsificante água em óleo $(A E a / o)$ foi definida como a quantidade de biossurfactante ne- 
cessária para manter a emulsão estável por 24 h, conforme a Equação 30.

$$
A E_{a / o}=E_{24(\text { amostra })}-E_{24(\text { branco })} * D
$$

Onde $A E_{a / o}=$ atividade emulsificante água em óleo (UE); $E_{24(\text { branco) }}=$ relação centesimal entre a altura da emulsão água/óleo e a altura total, utilizando água em vez de amostra e $D=$ diluição da amostra.

\subsection{Extração do biossurfactante}

Após o cultivo, a biomassa fúngica foi separada por filtração a vácuo, e o filtrado obtido foi acidificado até $\mathrm{pH} 2,0$ usando-se $\mathrm{HCl} 6 \mathrm{~N}$, e foi mantido a $4{ }^{\circ} \mathrm{C}$ durante $12 \mathrm{~h}$ e centrifugado $\left(4500 \mathrm{x} \mathrm{g} ; 30 \mathrm{~min}, 4^{\circ} \mathrm{C}\right)$. Isopropanol foi utilizado no filtrado para a precipitação do biossurfactante até a exaustão 0 , estipulado 20 dias como tempo de exaustão. O precipitado resultante foi recolhido por centrifugação a $6000 \mathrm{~min}^{-1}$, a $4{ }^{\circ} \mathrm{C}$ durante 30 min. O sobrenadante foi removido e $10 \mathrm{~mL}$ de clorofórmio e metanol $(2: 1, \mathrm{v} / \mathrm{v})$ foi adicionado ao precipitado seguido de agitação rotativa a $200 \mathrm{~min}^{-1}, 30{ }^{\circ} \mathrm{C}$ durante $20 \mathrm{~min}$. A mistura foi deixada em repouso para decantação, o sobrenadante foi retirado com auxílio de uma pipeta e o precipitado foi deixado em temperatura ambiente para evaporação do solvente e em seguida foi liofilizado 0 .

Foi realizado também o procedimento de extração no meio de cultivo no tempo inicial, sem inoculação, para usá-lo como branco nas análises químicas e de grupos funcionais por FTIR (Espectroscopia de Infravermelho com Transformada de Fourier).

A análise da tensão superficial foi realizada em uma solução com concentração de $1 \mathrm{~g} / \mathrm{L}$ dos biossurfactantes extraídos para comparação com a tensão superficial da água destilada $(72 \mathrm{mN} / \mathrm{m})$ e verificar $R T$.

\subsection{Análise da composição química do biossurfactante}

Após o processo de extração, a composição química do biossurfactante bruto foi determinada em termos de proteína 0 e carboidrato total 0 .

\subsection{Espectroscopia de infravermelho com transformada de Fourier (FTIR)}

A identificação de grupos funcionais foi realizada por espectroscopia de infravermelho com transformada de Fourier (FTIR). Os espectros de FTIR foram registados num espectrômetro Perkin Elmer FTIR - FROMTIER na região espectral de infravermelho médio $4000-400 \mathrm{~cm}^{-1}$. O biossurfactante extraído e seco foi analisado e uma pastilha de $\mathrm{KBr}$ foi utilizada como referência de fundo.

\subsection{Análise estatística}

Os resultados em triplicata da tensão superficial, do índice de emulsificação $\left(\mathrm{E}_{24}\right)$ e da atividade emulsificante $\left(A E_{a / o}\right)$ foram submetidos à análise de variância dos valores médios das amostras, através do Teste de Tukey com nível de significância de 5\% (ANOVA).

\section{RESULTADOS E DISCUSSÃO}

\subsection{Produção dos biossurfactantes}

Os experimentos utilizando óleo de soja comercial (B1) e utilizando óleo de soja residual de fritura (B2), foram conduzidos em biorreator de bancada com volume útil de $4 \mathrm{~L}$, e foram analisados em termos de tensão superficial, concentração de biomassa micelial e atividade emulsificante. A Figura 1 corresponde aos resultados obtidos no experimento B1 (Figura 1A) e no experimento B2 (Figura 1B).

Pode-se observar na Figura 1A que houve redução na tensão superficial até 144 h (6 dias) de cultivo, com uma diminuição de tensão superficial (de 45,1 para $43,42 \mathrm{mN} / \mathrm{m}$ ) o que equivale a $R T$ de $3,73 \%$. Para o experimento B2, que foi realizado com óleo de soja residual de fritura (Figura 1B) houve uma maior redução da tensão superficial (de 44,65 para 40,68 mN/m) ou seja, $R T$ de 8,89\%, após 192 h ( 8 dias), mantendo-se assim até o final do cultivo.

Bezerra et al. 0 utilizando uma cepa de Pseudomonas aeruginosa isolada de poços de petróleo de Canto do Amaro/Moçoró/RN, sob o código de AP029/GLVIIA obtiveram como melhor resultado o ensaio com agitação de $200 \mathrm{~min}^{-1}$, razão de aeração (definida pela razão entre o volume do meio e o volume do frasco $-\mathrm{V}_{\mathrm{m}} / \mathrm{V}_{\mathrm{f}}$ ) de 0,8 , e a $30^{\circ} \mathrm{C}$, onde a tensão superficial foi de $30,92 \mathrm{mN} / \mathrm{m}$. Os autores ainda ressaltaram que as variáveis que mais contribuíram para esse resultado foram a temperatura e a razão de aeração. 

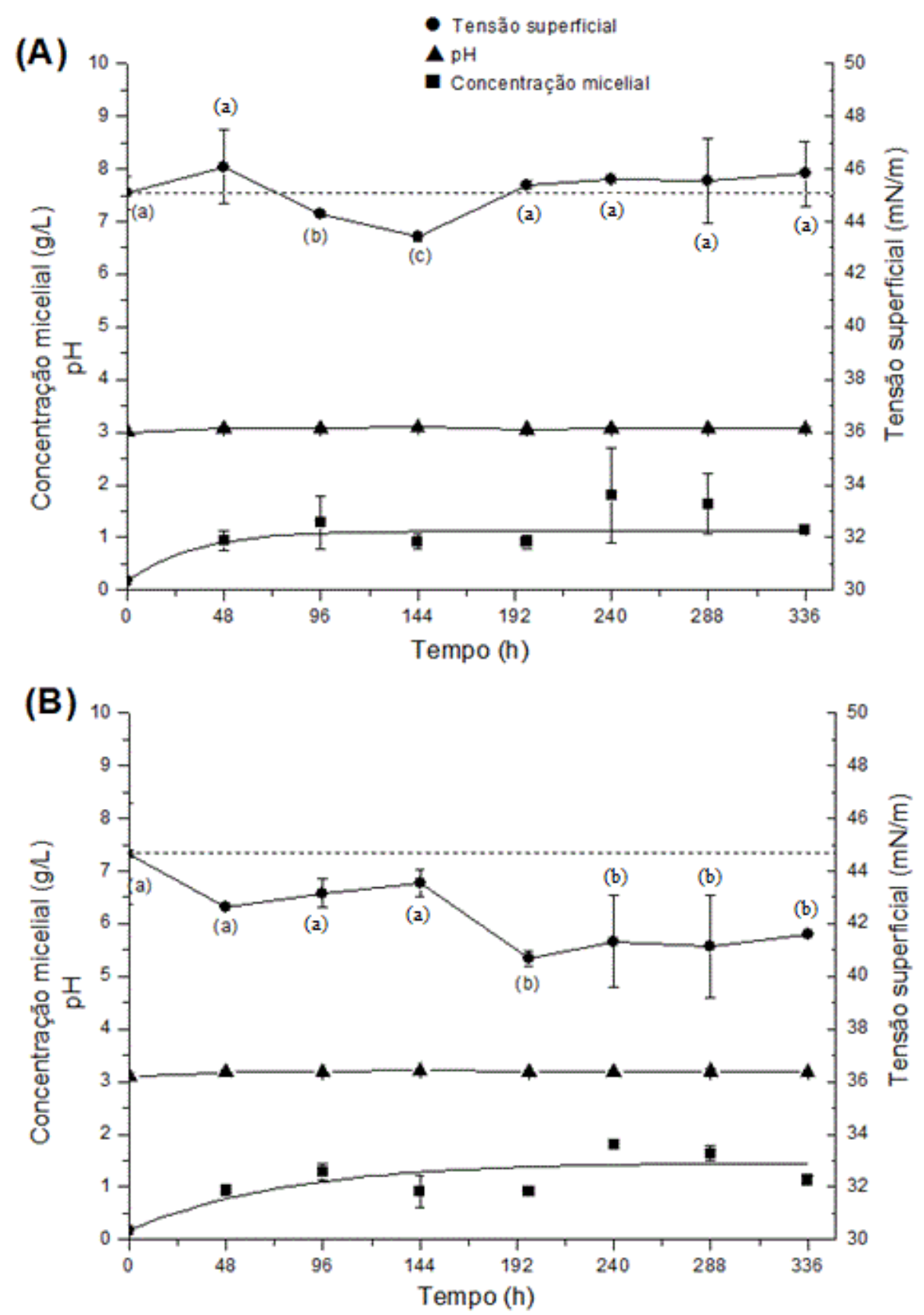

Figura 1: Variações das concentrações de biomassa micelial $(\mathrm{g} / \mathrm{L})$, da tensão superficial $(\mathrm{mN} / \mathrm{m})$ e do $\mathrm{pH}$ em função do tempo (h) no cultivo de P. sajor-caju, com óleo de soja comercial (A) e óleo de soja residual de fritura (B). Os pontos equivalem aos valores médios da duplicata dos ensaios e as barras ao desvio médio. A linha tracejada foi utilizada para auxiliar na visualização da variação da tensão superficial. Médias com letras distintas diferem significativamente pelo teste de Tukey $(\mathrm{p} \leq 0,05)$.

Velioglu e Urek 0 quando cultivaram P. sajor-caju em cultivo sólido, extraíram um biossurfactante com uma tensão superficial de $41,93 \pm 0,7 \mathrm{mN} / \mathrm{m}$ após 16 dias de fermentação. Esse valor foi similar ao encontrado no experimento B1 $(43,42 \pm 0,15 \mathrm{mN} / \mathrm{m})$ e no experimento B2 $(40,68 \pm 0,78 \mathrm{mN} / \mathrm{m})$, no entanto em menores tempos de cultivo, 6 e 8 dias, respectivamente.

Observa-se ainda na Figura 1 que a utilização do óleo de soja residual de fritura (Figura 1B) proporcionou maior valor de $R T$ que o óleo de soja comercial, sugerindo que este tipo de resíduo pode ser utilizado na produção de biossarfactantes por P.sajor-caju. 
O valor máximo de biomassa encontrado para o experimento B1 foi de 1,08 $\pm 0,09 \mathrm{~g} / \mathrm{L}$ (Figura 1A) e para o experimento B2 foi de 1,79 $\pm 0,91 \mathrm{~g} / \mathrm{L}$ (Figura 1B), esses valores são inferiores ao reportado por Borges et al. 0 que utilizando Pleurotus djamor cultivado em meio POL (meio comumente utilizado para produção de polissacarídeos) em pH 3, aeração mantida em 0,25 L/min, agitação em $300 \mathrm{~min}^{-1}$, e com $40 \mathrm{~g} / \mathrm{L}$ de glicose, obtiveram aproximadamente $8 \mathrm{~g} / \mathrm{L}$ de biomassa em 14 dias $(336 \mathrm{~h})$ de fermentação. Apesar de nos experimentos B1 e B2 terem sido encontrados baixos valores de concentração micelial, esse fato não deve ser atribuído ao valor de $\mathrm{pH}$, visto que Borges et al. 0 também utilizaram um $\mathrm{pH}$ ácido igual a 3,0 porém com o emprego de glicose. Ainda, observa-se que o $\mathrm{pH}$ não variou durante o cultivo, tanto nos experimentos $\mathrm{B} 1 \mathrm{e}$ B2, da mesma forma que no experimento de Borges et al. 0 cujo valor foi controlado em 3 durante todo o processo.

$\mathrm{Na}$ Tabela 1 estão os resultados do Índice de Emulsificação $\left(\mathrm{E}_{24}\right)$ e da Atividade Emulsificante $\left(\mathrm{AE}_{\mathrm{a} / \mathrm{o}}\right)$ para o experimento B1 em $144 \mathrm{~h}$ (6 dias) e para o experimento B2 em $192 \mathrm{~h}$ (8 dias).

Tabela 1: Índice de Emulsificação $\left(\mathrm{E}_{24}\right)$ e Atividade Emulsificante $\left(\mathrm{AE}_{\mathrm{a} / \mathrm{o}}\right)$ para os experimentos $\mathrm{B} 1 * \mathrm{e} \mathrm{B} 2 * *$.

\begin{tabular}{c|c|c}
\hline Experimentos & $\mathbf{E}_{\mathbf{2 4}}(\mathbf{\%})$ & $\begin{array}{c}\mathbf{A E}_{\mathbf{a} / \mathbf{o}} \\
\text { (Unidades emulsificantes - UE) }\end{array}$ \\
\hline B1 & $66,6 \% \pm 0,0^{\mathrm{a}}$ & $28,2 \pm 2,8^{\mathrm{a}}$ \\
B2 & $65,8 \% \pm 2,8^{\mathrm{a}}$ & $27,3 \pm 2,8^{\mathrm{a}}$ \\
\hline
\end{tabular}

*B1 - Com óleo de soja comercial. **B2 - Com óleo de soja residual de fritura.

Médias na mesma coluna seguidas por letras distintas diferem significativamente pelo teste de Tukey $(\mathrm{p} \leq$ $0,05)$.

Velioglu e Urek 0 utilizando Pleurotus sajor-caju em cultivo sólido, alcançaram um valor de índice de emulsificação sobre óleo de soja de $54,55 \% \pm 4,00$ após 16 dias de fermentação. Velioglu e Urek 0 cultivando Pleurotus ostreatus em cultivo submerso, obtiveram valor máximo de índice de emulsificação sobre óleo de soja de $60 \% \pm 5,00$ após 13 dias de fermentação. Esses valores são inferiores ao encontrado no presente trabalho (Tabela 1), cujos índices de emulsificação foram alcançados em menor tempo de cultivo.

Já, Penicillium expansum cultivado em meio contendo bagaço de cana como substrato e óleo residual de fritura como substrato adicional, alcançou um índice de emulsificação sobre tolueno de $45,8 \%$ após $168 \mathrm{~h}$ de fermentação 0 .

O índice de emulsificação pode ser alterado de acordo com a afinidade do biossurfactante produzido pelo micro-organismo e o hidrocarboneto utilizado para a emulsificação. Por esse fato é que existem tantas variações de índice de emulsificação reportados na literatura.

As atividades emulsificante água em óleo $\left(\mathrm{AE}_{\mathrm{a} / \mathrm{o}}\right)$ médias do experimento $\mathrm{B} 1 \mathrm{em} 144 \mathrm{~h}(6$ dias) e do experimento B2 em $192 \mathrm{~h}$ (8 dias) foram de 28,2 $\pm 2,8$ (UE) e 27,3 $\pm 2,8 \mathrm{UE}$, respectivamente (Tabela 1).

Pinto et al. 0, cultivando a bactéria Corynebacterium aquaticum, obtiveram o valor máximo de $\mathrm{AE}_{\mathrm{a} / \mathrm{o}}$ $(24,84 \pm 2,47 \mathrm{UE})$ em $60 \mathrm{~h}$ de fermentação, valor muito semelhante ao encontrado no presente trabalho.

Colla et al. 0 cultivando o fungo Aspergillus sp. em cultivo submerso, alcançaram 42,67 $\pm 6,65 \mathrm{UE}$ de valor máximo de $\mathrm{AE}_{\mathrm{a} / \mathrm{o}}$ em $72 \mathrm{~h}$ de fermentação.

Pseudomonas aeruginosa e Bacillus pumilus isolados de solo contaminado com óleo diesel, apresentaram atividade emulsificante de 201,6 UE em 5 dias e 154,5 UE em 2 dias de fermentação, respectivamente 0 . Estes valores são superiores aos encontrados no presente trabalho. Isso se deve ao fato de que para estes dois micro-organismos existem vários estudos de otimização de produção de biossurfactante 0 , enquanto que para o gênero Pleurotus ainda são poucos os estudos referentes a produção de tensoativos 0 .

Sendo a atividade emulsificante água em óleo $\left(\mathrm{AE}_{\mathrm{a} / \mathrm{o}}\right)$ definida como a quantidade de biossurfactante necessária para manter a emulsão estável por $24 \mathrm{~h}$, pode-se sugerir que o meio de cultivo e o microorganismo proposto neste trabalho tem potencial para produção de biossurfactante.

\subsection{Extração e caracterização dos biossurfactantes}

Após decorrido o tempo de fermentação (14 dias), a biomassa e o óleo foram separados do caldo de cultivo. $\mathrm{O}$ caldo foi submetido à extração e o biossurfactante obtido foi caracterizado em termos de carboidratos, proteínas e grupos funcionais.

Uma alta concentração de biossurfactante é importante, bem como um biossurfactante ativo. O rendi- 
mento de produção e a atividade do biossurfactante são baseados em requisitos nutricionais dos microorganismos e de parâmetros de crescimento 0 . No presente trabalho obteve-se $0,70 \pm 0,03 \mathrm{~g} / \mathrm{L}$ de biossurfactante para o experimento utilizando óleo de soja comercial (B1) e $0,63 \pm 0,04 \mathrm{~g} / \mathrm{L}$ para o experimento utilizando óleo de soja residual de fritura (B2).

O meio de cultivo no tempo inicial (branco), que foi submetido à extração dos biossurfactantes, não apresentou precipitação de nenhum composto. Assim, pode-se afirmar que o composto extraído (biossurfactante) dos experimentos B1 e B2 foi formado durante o cultivo submerso de P. sajor-caju.

Velioglu e Urek 0 obtiveram concentrações de biossurfactantes de 2,8 \pm 0,2 g/L; 2,4 \pm 0,2 g/L e 4,0 \pm 0,3 g/L produzidos em cultivo sólido de Pleurotus djamor, P. eryngii e P. sajor-caju, respectivamente. Já, $P$. ostreatus em cultivo sólido, com agitação, produziu 4,7 $\pm 0,2 \mathrm{~g} / \mathrm{L}$ de biossurfactante e sem agitação, $4,1 \pm 0,2 \mathrm{~g} / \mathrm{L} 0$. Velioglu e Urek 0 obtiveram concentrações de biossurfactantes superiores às encontradas no presente trabalho. A diferença obtida principalmente para a espécie $P$. sajor caju se deve, provavelmente ao fato de que os autores realizaram fermentação em estado sólido. Velioglu e Urek 0 relatam que a composição química do biossurfactante extraído do cultivo sólido de P. ostreatus foi de $12,5 \pm 0,9 \%$ de carboidrato e $19,1 \pm 1,1 \%$ de proteínas, o que indica uma estrutura complexa para o biossurfactante. No presente trabalho, os biossurfactantes extraídos dos experimentos B1 e B2 apresentaram 12,0 $\pm 0,5 \%$ e 10,6 $\pm 0,6 \%$ de carboidratos, 7,4 $\pm 0,6 \%$ e 7,7 $\pm 1,0 \%$ de proteínas, respectivamente, valores estes, similares aos encontrados por Velioglu e Urek 0 .

Ao analisar a tensão superficial das soluções de $1 \mathrm{~g} / \mathrm{L}$ dos biossurfactantes extraídos, obteve-se os valores de $54,2 \pm 0,1 \mathrm{mN} / \mathrm{m}$ e $49,9 \pm 0,05 \mathrm{mN} / \mathrm{m}$ para os biossurfactantes dos experimentos B1 e B2, respectivamente. Quando esses valores são comparados com o valor da tensão superficial da água destilada (72 $\mathrm{mN} / \mathrm{m}$ ), a redução da tensão superficial é de 24,76\% (B1) e 30,74\% (B2). Esses resultados corroboram com a sugestão da troca do óleo de soja comercial por óleo de soja residual de fritura.

Os espectros de FTIR dos biossurfactantes extraídos dos experimentos realizados com óleo de soja comercial (B1) e com óleo de soja residual de fritura (B2) podem ser visualizados na Figura 2.

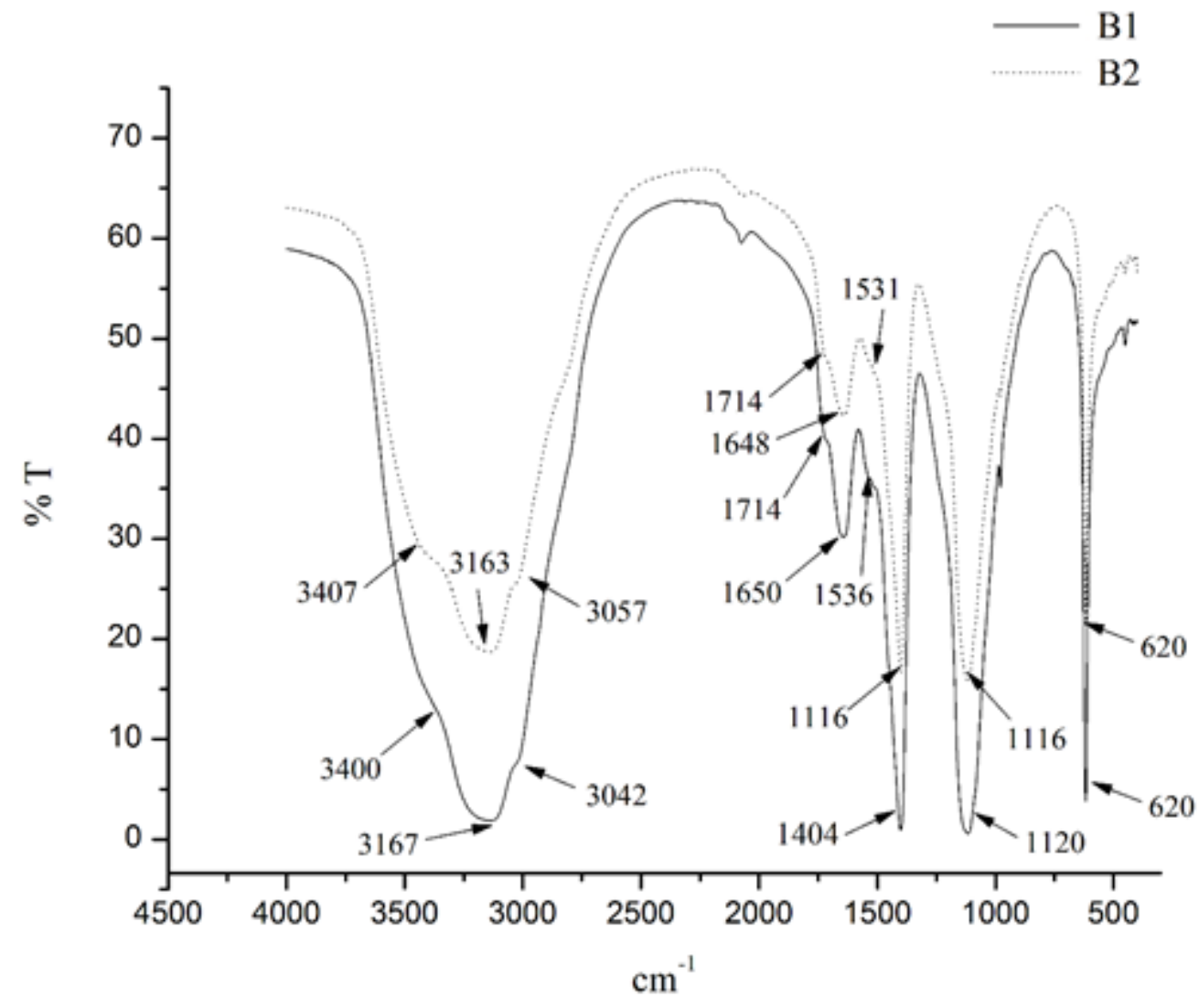

Figura 2: Comparação dos espectros de infravermelho com transformada de Fourier (FTIR) dos biossurfactantes extraídos dos experimentos realizados com óleo de soja comercial (B1) e o com óleo de soja residual de fritura (B2).

Observa-se na Figura 2, que os espectros dos experimentos B1 e B2 são muito semelhantes, diferenci- 
ando-se apenas pela intensidade dos picos.

Verifica-se que o alongamento de $=\mathrm{C}-\mathrm{H}\left(3042 \mathrm{~cm}^{-1}\right.$ para B1 e $3057 \mathrm{~cm}^{-1}$ para B2) combinado com alongamento de $\mathrm{C}=\mathrm{C}\left(1650 \mathrm{~cm}^{-1}\right.$ para $\mathrm{B} 1 \mathrm{e} 1648 \mathrm{~cm}^{-1}$ para B2 $) 0$ e flexão de $=\mathrm{C}-\mathrm{H}$ fora do plano $\left(620 \mathrm{~cm}^{-1}\right.$ para B1 e B2) 0 caracterizam a presença da cadeia de um alceno. Observa-se também a presença da banda do alongamento de C-O-C $\left(1120 \mathrm{~cm}^{-1}\right.$ para B1 e $1116 \mathrm{~cm}^{-1}$ para B2) 0que caracteriza a presença de carboidratos.

A banda característica de alongamento C-C alifático $\left(1404 \mathrm{~cm}^{-1}\right.$ para B1 e $1402 \mathrm{~cm}^{-1}$ para B2) está presente em ambos os espectros e pode estar relacionada com a cadeia de polissacarídeo do biossurfactante 0 . Também está presente a banda do alongamento simétrico de $\mathrm{NH}_{2}\left(3167 \mathrm{~cm}^{-1}\right.$ para $\mathrm{B} 1$ e $3163 \mathrm{~cm}^{-1}$ para B2) que sugere a presença do grupo funcional amida 0 e a banda do alongamento de $\mathrm{C}=\mathrm{O}$, presentes no espectro em $1714 \mathrm{~cm}^{-1}$, que sugere a presença de éster de lipídeo [26]. Observa-se no espectro um ombro que pode ser atribuído à banda de $\mathrm{N}-\mathrm{H}\left(1531 \mathrm{~cm}^{-1}\right.$ para $\mathrm{B} 1 \mathrm{e} 1536 \mathrm{~cm}^{-1}$ para $\left.\mathrm{B} 2\right)$, o que sugere a presença de proteínas 0 .

As bandas do alongamento de O-H [25] em (3400 $\mathrm{cm}^{-1}$ para B1 e $3407 \mathrm{~cm}^{-1}$ para B2) podem ser encontradas no espectro de ambos os experimentos. Observou-se também que ambos os espectros não apresentaram bandas características de heteroátomos. Sugere-se que a estrutura do biossurfactante extraído em ambos os experimentos (B1 e B2) seja um complexo que contenha carboidrato-proteína-lipídeo.

Velioglu e Urek 0 analisaram por meio de FTIR os biossurfactantes extraídos do micélio do cultivo sólido com e sem agitação de Pleurotus ostreatus, e identificaram bandas associadas a resíduos de açúcares, e também a presença de proteínas por meio das bandas de $\mathrm{C}=\mathrm{O}\left(1659 \mathrm{~cm}^{-1}\right)$ e N-H $\left(1530 \mathrm{e} 1535 \mathrm{~cm}^{-1}\right)$. Também identificaram a banda característica de cadeia de hidrocarboneto (1200-1400 $\left.\mathrm{cm}^{-1}\right)$. Os autores sugerem que os biossurfactantes extraídos apresentam características de uma estrutura complexa de carboidratopeptídeo-lipídeo. Essa estrutura é característica da classe de biossurfactantes poliméricos, os quais são mais eficientes na estabilidade de emulsões, chamados de bioemulsificantes 0 .

Os biossurfactantes extraídos do micélio do cultivo sólido de Pleurotus sajor-caju, ao serem analisados por FTIR, apresentaram bandas associadas a lipídeos e resíduos de açúcares, e também a função carbonila presente em radicais carboxilas ou amidas de proteínas e aminas peptídicas 0 . Os autores sugerem que o biossurfactante extraído possui uma estrutura complexa de proteína-polissacarídeo-lipídeo.

Dalonso et al. 0 ao caracterizar um extrato proveniente de corpos frutíferos de Pleurotus sajor-caju identificaram bandas características de carboidratos (C-O-C de 900 a $1200 \mathrm{~cm}^{-1}$ ) e proteínas (1664 e 1527 $\mathrm{cm}^{-1}$ ). No entanto, devido à complexidade do espectro os autores acreditam que a composição dos extratos pode ser uma mistura de polissacarídeos, incluindo a possibilidade de heteropolímeros.

\section{CONCLUSÕES}

No cultivo em biorreator utilizando óleo de soja comercial observou-se uma diminuição de tensão superficial (de 45,1 para $43,42 \mathrm{mN} / \mathrm{m}$ ) o que equivale a uma $R T$ de $3,73 \%$ em 6 dias de cultivo. Quando o experimento foi realizado com óleo de soja residual de fritura houve uma maior redução da tensão superficial (de 44,65 para $40,68 \mathrm{mN} / \mathrm{m}$ ) ou seja, $R T$ de $8,89 \%$ após 8 dias de cultivo. Esses resultados sugerem que este tipo de resíduo pode ser utilizado na produção de biossarfactantes por P.sajor-caju.

$\mathrm{O}$ índice de emulsificação e a atividade emulsificante água em óleo $\left(\mathrm{AE}_{\mathrm{a} / \mathrm{o}}\right)$ após $24 \mathrm{~h}(66,6 \%$ e 28,2 UE, respectivamente, no experimento com óleo de soja comercial, e 65,8\% e 27,3 UE, respectivamente, no experimento com óleo de soja residual de fritura), são similares aos valores reportados na literatura para o mesmo gênero de micro-organismo, utilizando óleo de soja como hidrocarboneto. $\mathrm{O}$ índice de emulsificação pode ser alterado de acordo com a afinidade do biossurfactante pelo hidrocarboneto utilizado, sendo a atividade emulsificante água em óleo $\left(\mathrm{AE}_{\mathrm{a} / \mathrm{o}}\right)$ definida como a quantidade de biossurfactante necessária para manter a emulsão estável por $24 \mathrm{~h}$. Pode-se sugerir que o meio de cultivo e o micro-organismo proposto neste trabalho tem potencial para produção de biossurfactante.

Nas análises dos espectros de FTIR pode-se identificar bandas que confirmam a presença de carboidratos e proteínas e sugere a presença de lipídeos. Portanto sugere-se que a estrutura do biossurfactante seja um complexo que contenha carboidrato-proteína-lipídeo e possa ser utilizado como emulsionante, assim como reportado na literatura.

\section{AGRADECIMENTOS}

À FURB, pela parceria e realização das análises de tensão superficial. À CAPES pela concessão da bolsa de estudos ao longo do curso de mestrado.

\section{BIBLIOGRAFIA}


[1] MARTINS, A.B., LOPES, C.V., AVELINO, M.C.G.S. "Reciclagem de óleos residuais de fritura: rotas para a reutilização", Revista Conexão Eletrônica, v.13, n. 1, pp. 997-1005, 2016.

[2] RODRIGUES, G.T., ALMEIDA, G.M., ALVES, R.S.V., et al. "Estudo da viabilidade econômica de implantação de uma Indústria de produção de biodiesel utilizando óleo de cozinha saturado no município de Campos dos Goytacazes", Perspectivas online, v. 5, n. 17, pp. 2-14, 2011.

[3] VELOSO, Y.M.S., LIMA E FREITAS, L.F., et al.,. "Rotas para reutilização de óleos residuais de fritura", Cadernos de Graduação - Ciências Exatas e Tecnológicas, v. 1, n.15, p. 11-18, 2012.

[4] COSTA, S.G.V.A.O., NITSCHKE, M., CONTIERO, J. "Produção de biotensoativos a partir de resíduos de óleos e gorduras", Ciência e Tecnolologia de Alimentos, v. 28, n. 1, pp. 34-38, 2008.

[5] RAHMAN, P.K.S.M., GAKPE, E. "Production, characterization and application of biosurfactants", Biothecnology, v. 7, n. 2, pp. 360-370, 2008.

[6] KOSARIC, N. "Biosurfactants in industry", Pure \& Applied Chemistry, v. 64, n. 11, pp. 1731-1737, 1992.

[7] SHEPHERD, R., ROCKEY, J., SUTHERLAND, I.W., et al. "Novel bioemulsifiers from microorganisms for use in foods", Journal of Biotechnology, v. 40, n. 3, p. 207-217, 1995.

[8] LUNA, J. M., SARUBBO, L., CAMPOS-TAKAKI. G.M. "A New Biosurfactant Produced by Candida glabrata UCP 1002: Characteristics of stability and application in oil recovery", Brazilian Archives of Biology and Technology, v. 52, n. 4, pp. 785-793, 2009.

[9] VELIOGLU, Z., UREK, R. O. "Concurrent biosurfactant and ligninolytic enzyme production by Pleurotus spp. in solid-state fermentation", Applied Biochemistry and Biotechnology, v. 174, n.4, pp. 1354-1364, 2014.

[10] VELIOGLU, Z., UREK, R.O. "Biosurfactant production by Pleurotus ostreatus in submerged and solidstate fermentation systems", Turkish Journal of Biology, v. 39, n.1, pp. 160-166, 2015.

[11] MUSHWORLD. Oyster mushroom cultivation (Mushroom Growers' Handbook 1), Korea, MushWorld, 2004.

[12] FONTES, G.C., AMARAL, P.F.F., COELHO, M.A.Z. "Produção de biossurfactante por levedura", Química Nova, v. 31, n. 8, pp. 2091-2099, 2008.

[13] RUFINO, R.D., SARUBBO, L.A., NETO, B.B., et al.,"Experimental design for the production of tensio-active agent by Candida lipolytica". Journal of Industrial Microbiology and Biotechnology, v. 35, n.8, pp. 907-914, 2008.

[14] WISBECK, E., FURLAN, S.A., NINOW, J.L. "Efeito da concentração inicial de glicose e do pH na produção de exopolissacarídeos de potencial antitumoral por Pleurotus ostreatus DSM 1833", Revista Saúde e Ambiente / Health and Environment Journal, v. 6, n.2, pp. 19-22, 2005.

[15] PINTO, M.H., MARTINS, R.G., COSTA, J.A.V. "Bacteria biosurfactants production kinetic evaluation", Química Nova, v. 32, n. 8, pp. 2104-2108, 2009.

[16] JAIN, R.M., MODY, K., MISHRA, A., et al., "Isolation and structural characterization of biosurfactant produced by an alkaliphilic bacterium Cronobacter sakazakii isolated from oil contaminated wastewater", Carbohydrate Polymers, v. 87, n.3, pp. 2320-2326, 2012.

[17] CHANDER, C.R.S, LOHITNATH, T., KUMAR, D.J.M., et al., "Production and characterization of biosurfactant from Bacillus subtilis MTCC441 and its evaluation to use as bioemulsifier for food biopreservative", Advances in Applied Science Research, v. 3, n.3, pp. 1827-1831, 2012.

[18] LOWRY, O.H., ROSEBROUGH, N.J., FARR, A.L., et al., "Protein measurement with the folin phenol reagent", Journal of Biological Chemistry, v. 193, pp. 265-276, 1951.

[19] DUBOIS, M., GILLES, K.A., HAMILTON, J.K., et al., "Colorimetric method for determination of sugars and related substances", Analytical Chemistry, v. 28, n.3, pp. 350-356, 1956.

[20] BEZERRA, M.S., HOLANDA, V.C.D., AMORIM, J.A., et al., "Produção de biotensoativo utilizando Pseudomonas aeruginosa (P.A.) e resíduo agroindustrial (manipueira) como substrato", Holos, v. 1, p. 14-27, 2012.

[21] BORGES, G.M., SCHIEBELBEIN, A.P., BARBA, F.F.M., et al., "Extracellular polysaccharide production by a strain of Pleurotus djamor isolated in the south of Brazil and antitumor activity on Sarcoma 180", Brazilian Journal of Microbiology, v. 44, n.4, pp. 1059-1065, 2013.

[22] LIMA, B.M., Produção de biossurfactantes pelos fungos Aspergillus ochraceus e Penicillium expansum em fermentação semi-sólida utilizando resíduos agorindustriais como substrato, Dissertação MSc., UNESP, São José do Rio Preto, SP, Brasil, 2012. 
[23] COLLA, L.M., RIZZARDI, J., PINTO, M.H., et al., "Simultaneous production of lipases and biosurfactants by submerged and solid-state bioprocesses", Bioresource Technology, v. 101, n. 21, pp. 8308-8314, 2010.

[24] DECESARO, A., RIGON, M.R., THOMÉ, A., et al., "Produção de biossurfactantes por microrganismos isolados de solo contaminado com óleo diesel”, Química Nova, v. 36, n. 7, pp. 947-954, 2013.

[25] STUART, B. Infrared spectroscopy: fundamentals and aplications. Chichester, John Wiley \& Sons Ltd., 2004.

[26] LOPES, W.A., FASCIO, M. "Esquema para interpretação de espectros de substâncias orgânicas na região do Infravermelho", Química Nova, v. 27, n. 4, pp. 670-673, 2004.

[27] DALONSO, N., GOLDMAN, G.H., GERN, R.M.M. “ $\beta-(1 \rightarrow 3)(1 \rightarrow 6)$ Glucans: medicinal activities, characterization, biosynthesis and new horizons", Applied Microbiology and Biotechnology, v. 99, n. 19, pp. 7893-7906, 2015.

[28] KOZARSKI, M.S., KLAUS, A.S., NIKŠIĆ, M.P., et al., "Polysaccharides of higher fungi: biological role, structure and antioxidative activity”, Hemijska industrija (Chemical Industry), v. 68, n. 3, pp. 305-320. 2014.

[29] DALONSO, N., SOUZA, R., SILVEIRA, M.L.L., et al., "Characterization and antineoplasic effect of extracts obtained from Pleurotus sajor-caju fruiting bodies", Applied Biochemistry and Biotechnology, v. 160, n. 8, pp. 2265-2274, 2010. 